\title{
Cervical spine injuries in pediatric athletes: mechanisms and management
}

\author{
Jay Jagannathan, M.D., Aaron S. Dumont, M.D., Daniel M. Prevedello, M.D., \\ Christopher I. Shaffrey, M.D., AND John A. JANE JR., M.D.
}

Department of Neurological Surgery, University of Virginia Health Sciences Center, Charlottesville, Virginia

\begin{abstract}
$\checkmark$ Sports-related injuries to the spine, although relatively rare compared with head injuries, contribute to significant morbidity and mortality in children. The reported incidence of traumatic cervical spine injury in pediatric athletes varies, and most studies are limited because of the low prevalence of injury. The anatomical and biomechanical differences between the immature spine of pediatric patients and the mature spine of adults that make pediatric patients more susceptible to injury include a greater mobility of the spine due to ligamentous laxity, shallow angulations of facet joints, immature development of neck musculature, and incomplete ossification of the vertebrae. As a result of these differences, 60 to $80 \%$ of all pediatric vertebral injuries occur in the cervical region. Understanding pediatric injury biomechanics in the cervical spine is important to the neurosurgeon, because coaches, parents, and athletes who place themselves in positions known to be associated with spinal cord injury (SCI) run a higher risk of such injury and paralysis. The mechanisms of SCI can be broadly subclassified into five types: axial loading, dislocation, lateral bending, rotation, and hyperflexion/hyperextension, although severe injuries often result from a combination of more than one of these subtypes. The aim of this review was to detail the characteristics and management of pediatric cervical spine injury.
\end{abstract}

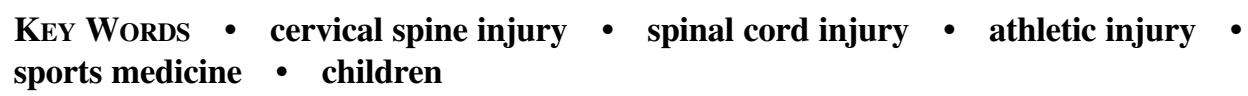

A PPROXIMATELY 3.5 million children are injured annually while participating in sports or recreational activities. ${ }^{32}$ Although intracranial injuries outnumber spine injuries, ${ }^{3}$ athletic activities are one of the leading causes of cervical spine injuries in the pediatric population. ${ }^{10}$ When they occur, sports-related injuries are often viewed by healthcare providers as "chance" or "freak" accidents. On the basis of our current understanding of cervical spine biomechanics, however, it is possible to identify the mechanisms and forces that put the pediatric athlete at risk for cervical spine injury.

\section{Developmental Considerations}

The fulcrum of the cervical spine descends as the pediatric spine matures. In children younger than 8 years, the maximal mobility occurs between the $\mathrm{C}-1$ and $\mathrm{C}-3$ region. In 8- to 12-year-old children, the fulcrum of cervical spine flexion changes to $\mathrm{C} 3-5 .{ }^{15}$ After the child reaches the age of 12 years, the fulcrum moves to the C5-6 region, where it remains throughout adulthood. Injuries due to flexionextension, which occur commonly in motor vehicle accidents, for example, tend to reflect these factors. This also explains the observation that younger children tend to be at higher risk for upper cervical spine injury. ${ }^{9}$

The first two cervical vertebrae are unique in their de-

Abbreviations used in this paper: CT = computed tomography; $\mathrm{MR}=$ magnetic resonance; $\mathrm{SCI}=$ spinal cord injury; SCIWORA = SCI without radiographic abnormality; VB = vertebral body. velopment. The atlas $(\mathrm{C}-1)$ is formed by three primary ossification sites: the anterior arch and two neural arches, which surround the anterior arch and fuse later in life to form the posterior arch. The anterior arch is ossified in only $20 \%$ of cases at birth and becomes visible as an ossification center by 1 year of age..$^{27}$ The neural arches appear in the 7th fetal week. The anterior arch fuses with the neural arches by 7 years of age; before this, lack of fusion may be mistaken for a fracture. The neural arches fuse posteriorly by 3 years of age. Occasionally, the anterior ossification center of C-1 does not develop and the neural arches attempt to fuse anteriorly. This fusion abnormality can be differentiated from a fracture in that it demonstrates sclerotic margins. ${ }^{6}$

The C-2 vertebra, or the axis, has the most complex and unique development of all the vertebrae. There are four ossification centers at birth: one for each neural arch, one for the VB, and one for the odontoid process. The odontoid process forms in utero from two separate ossification centers that fuse in the midline by the 7th month of gestation. A secondary ossification center appears at the apex of the odontoid process (os terminale) between 3 and 6 years of age and fuses by the age of 12 years. The body of C-2 fuses with the odontoid process by 3 to 6 years of age. This fusion line (subdental synchondrosis), or the remnant of the cartilaginous synchondrosis, can be seen until the age of 11 years and can be confused with a fracture. The neural arches fuse posteriorly by 2 to 3 years of age and with the body of the odontoid process between 3 and 6 years of age. 
The C3-7 levels are generally discussed as a unit because they exhibit the same developmental pattern. Three ossification sites are present: the VB, which arises from a single ossification site, and the two neural arches. ${ }^{29}$ The neural arches fuse posteriorly by the age of 2 to 3 years, and the VB fuses with the neural arches between 3 and 6 years of age. Additionally, secondary ossification centers can be seen at the tips of the transverse and spinous processes. These ossification centers can persist until early in the third decade of life, and simulate fractures. ${ }^{10,12} \mathrm{Se}$ condary ossification centers can also appear at the superior and inferior aspects of the cervical VBs and remain unfused until early adulthood.

Familiarity with the normal anatomy and ligaments of the craniocervical junction is also important for understanding mechanisms of injury. The anterior and posterior atlantooccipital membranes extend from the upper aspect of $\mathrm{C}-1$ to the anterior and posterior aspects of the foramen magnum. The anterior atlantoaxial ligament extends from the anterior midportion of the dens to the inferior aspect of the anterior arch of $\mathrm{C}-1 . .^{13}$ The tectorial membrane is the superior extension of the posterior longitudinal ligament and attaches to the anterolateral aspect of the foramen magnum, and it has stronger tensile strength than the apical or transverse ligament. ${ }^{24}$ The transverse ligament extends from the tubercle on the inner aspect of one side of the atlas to the tubercle on the other side. The apical ligament lies between the superior longitudinal fasciculus of the cruciform ligament and the anterior atlantooccipital membrane ${ }^{21}$ The alar ligaments connect the lateral aspect of the dens and the medial inferior aspect of the occipital condyles. The main function of the alar ligaments is to limit rotation to the contralateral side. Hence, an alar ligament tear results in a higher range of motion to the contralateral side, and rotational instability may result from this type of injury.

Cervical spine injuries in young children usually occur in the upper cervical levels, from the occiput to C-3. This fact is explained by the unique biomechanics and anatomy of the pediatric cervical spine. The fulcrum of motion in the cervical spine in children is at the $\mathrm{C} 2-3$ level, whereas in the adult cervical spine the fulcrum is at the C5-6 level. ${ }^{25,31}$ The immature spine is hypermobile because of ligamentous laxity, shallow and angled facet joints, underdeveloped spinous processes, and physiological anterior wedging of VBs, all of which contribute to high torque and shear forces acting on the C1-2 region. Incomplete ossification of the odontoid process, a relatively large head, and weak neck muscles are other factors that predispose the pediatric cervical spine to instability. ${ }^{6,24}$

The soft tissues surrounding the vertebral column also play a role in protecting the spinal cord from excessive movements. Muscle tone at the time of the injury can have a major influence on the force required to produce spinal cord damage, and ligamentous tissue provides stability throughout the vertebral column. The ligaments and soft tissues are generally more vulnerable to injury from rotational forces.

\section{Predisposing Conditions}

\section{Medical Conditions}

Certain conditions predispose the pediatric athlete to in- jury. Athletes with Down syndrome have a 10 to $40 \%$ incidence of occipitocervical and atlantoaxial instability due to extreme ligamentous laxity. This places them at a theoretically increased risk of cervical SCI. Despite increased participation by children with Down syndrome in sporting activities, the incidence of SCI in such athletes has not necessarily increased in comparison with the normal agematched population..$^{20}$ Patients with achondroplasia generally suffer from multiple levels of cervical spine stenosis. Often there is tight stenosis at the cervicomedullary junction at the foramen magnum. It has been found that patients with achondroplasia are at significant risk of SCI with hyperflexion and hyperextension..$^{28}$ Atlantoaxial instability is associated with mucopolysaccharidosis type VI (Maroteaux-Lamy syndrome), and atlantoaxial rotatory subluxation is seen in patients with Marfan syndrome.

\section{Cervical Stenosis}

Athletes found to have a congenitally narrow cervical vertebral canal (and who suffer head trauma) may be at higher risk of transient quadriplegia. Historically, the Torg ratio, which is a radiographic measure used to compare the spinal canal diameter to the VB width, had been viewed as a marker of spinal stenosis. ${ }^{33} \mathrm{~A}$ ratio of 0.8 or less indicates cervical stenosis and a higher risk of neurapraxia. ${ }^{23}$ When the sagittal canal/VB ratios were measured on lateral radiographs of the cervical spine obtained in 124 veteran and 100 rookie professional football players, however, $40(32 \%)$ of the 124 veterans and $34 \%$ of the 100 rookies had a ratio of less than 0.8 at one or more levels from C-3 to C-6. ${ }^{36}$ In view of the rarity of neurapraxia, the Torg ratio is no longer generally used to determine a patients' safety in athletic competition.

\section{Mechanisms of Injury}

Mechanisms of injury have been categorized into multiple subtypes. Some overlap exists, however, and some injuries can involve more than one mechanism (that is, axial loading with flexion producing bilateral jumped facets).

\section{Axial Loading}

Fractures resulting from pure vertical compression typically involve the C5-6 region, and they tend to be more stable. Generally, it is necessary for an injury mechanism to produce a rotational force to result in dislocation. ${ }^{34} \mathrm{Ax}-$ ial loading has received the most attention as a mechanism of injury in athletic competitions. Of 209 football-related injuries reported between 1971 and 1975, in 52\% of the patients who suffered from permanent quadriplegia the injury was attributed to axial loading. When the head is lowered, the buffering capacity of the cervical soft tissue diminishes, resulting in an increased amount of compressive forces on the cervical segments..$^{32}$ Furthermore, the cervical flexion obtained by lowering the head causes disappearance of the normally lordotic cervical spine, resulting in decreased ability of the cervical spine to absorb and dissipate energy. Consequently, the strain energy exceeds the absorptive capacity of the vertebral column. The result is often intervertebral disc space injury, VB fractures, or ligamentous injury. With additional loading, compressive forces result in buckling of the most unstable aspect of the 
spinal column. This buckling results in angulation or hyperflexion as a means of releasing additional energy. Compressive load limits of the cervical vertebrae have been calculated to be between 3340 and $4450 \mathrm{~N}$ in the young adult. These limits are easily reached when the head is lowered, at a velocity as low as $2.3 \mathrm{~m} / \mathrm{second}$, the equivalent of a fast walk. .8,35 $^{2}$

Axial loading injuries are often avoidable, and are brought about by intentionally using the crown of the head as a point of contact. On the basis of this observation, rule changes banning both deliberate "spearing" and the use of the top of the helmet as the initial point of contact in making a tackle were implemented at the high school and college levels in the late 1970s. Subsequently, a marked decrease in cervical spine injury rates occurred. Instances of permanent cervical-level quadriplegia decreased from 34 cases in 1976 to five in the 1984 season. ${ }^{14}$ Axial loading of the cervical spine has also been held responsible for catastrophic injuries in diving, rugby, ice hockey, and gymnastics. ${ }^{10}$ Implementation of appropriate changes in playing techniques and/or equipment modifications could possibly reduce the incidence of cervical spine injuries in these activities as well.

\section{Dislocation and Subluxation}

The cervical spine is particularly vulnerable to dislocation or subluxation when the injury mechanism involves rotation. A dislocation or subluxation normally results in the vertebrae becoming malaligned due to significant trauma to the head or neck. In some cases, this can result in jumped or locked facets. Accompanying damage to muscles and ligaments can often contribute to injuries and can sometimes compromise the vascular structures of the spinal cord. ${ }^{15}$

\section{Lateral Bending}

Cervical nerve roots are surrounded by a layer of vascular connective tissue that offers protection from injury; however, they are still susceptible to excessive tractional forces. Traction applied along a nerve root is absorbed along its length. As the elastic limits on the nerve's connective tissue are reached, disruption often occurs. Neurapraxia (that is, "stingers") is an example of neurological injury resulting from excessive traction on the peripheral nerves. Excessive lateral bending can place significant compressive and tractional forces on the spinal nerve roots as well as on the sheath of the dorsal nerve root. ${ }^{2,22}$

\section{Rotational Injuries}

Lateral bending in the cervical region is generally accompanied by rotation resulting from the oblique orientation of the superior and inferior facets. During rightward rotation of the axis on the atlas, the left transverse foramen of the atlas moves anteriorly, whereas the right transverse foramen moves posteriorly relative to the adjacent axis. As the rotation increases, the increased distance between adjacent transverse foramina results in increased tensile forces on the vertebral artery and spinal nerve. This can result in neurapraxia, or even in damage to the circulation of the brainstem or upper spinal cord in severe cases. ${ }^{1,10,29,34}$

The sensory changes of neurapraxia include burning pain, numbness, tingling, and loss of sensation, whereas the motor changes range from weakness to complete paralysis. The episodes are transient, and complete recovery usually occurs in 10 to 15 minutes, although in some patients gradual resolution occurs over a period of 36 to 48 hours. Except for burning paresthesia, pain in the neck is usually not present at the time of injury and there is complete return of motor function and full, pain-free motion of the cervical spine. Routine x-ray films of the cervical spine do not show fractures or dislocations. However, the $\mathrm{x}$-ray findings may include developmental spinal stenosis, congenital fusion, cervical instability, or intervertebral disc disease. ${ }^{16}$

\section{Hyperflexion/Hyperextension Injuries}

The pediatric atlantooccipital joint permits $10^{\circ}$ of flexion and $25^{\circ}$ of extension. The adult atlantooccipital joint provides approximately $15^{\circ}$ of flexion and extension. The remaining flexion and extension of the cervical region comes from the vertebral segments below. Overall, the range of motion throughout the cervical region is greater in children than in late adolescents or adults. In children up to 10 years of age, the flexion and extension are centered around C2-3, but this moves down to C4-5 and C5-6 after the age of 10 years. The C-2 normally moves forward on the C-3, up to 2 to $3 \mathrm{~mm}$ in pediatric patients. When the head is flexed this displacement is expected, and can be exaggerated in the presence of muscle spasm. This pseudosubluxation does not represent instability, even though significant angulation may be present.

Hyperflexion injuries are usually accompanied by some degree of rotation. Hyperflexion injuries that involve instability are often due to disruption of the posterior longitudinal ligament. Injuries involving a combination of hyperflexion and rotation can be exceptionally dangerous, because rotational forces can result in dislocation when combined with a hyperflexion force that disrupts the integrity of the supportive soft tissue. Injuries involving hyperflexion and rotation most commonly involve the C5-6 region in adolescents, but can be higher in young children. Hyperflexion may also result in ligamentous instability, which can result in a rapid decrease in the diameter of the spinal canal. This is often known as a pincer mechanism. ${ }^{19}$ In a pincer mechanism, the combination of an intervertebral disc along with degenerated facet and uncovertebral joints may invaginate the spinal canal. ${ }^{8}$ This protrusion into the spinal canal at the same level, as with extension of the neck, results in a likelihood of significant spinal cord compression in which there is a guillotine-like effect on the spinal cord.

Hyperextension injuries most commonly involve a fall. In athletics, this is often associated with a whiplash injury in which the forehead is struck. These injuries frequently involve the anterior longitudinal ligament rather than the spinal cord. Violent hyperextension, however, can damage the spinal cord as well, as a result of a pincer mechanism.

\section{Evaluating the Injured Pediatric Athlete}

Consideration of the mechanism of injury is an important step in the on-field assessment of the injured pediatric athlete. An athlete suffering from a major spinal injury 
may not immediately present with focal neurological signs or symptoms. ${ }^{16}$ While the player is still on the field, the prevention of further injury is the most important objective. ${ }^{7,11}$ Protective gear such as shoulder pads, helmet, and chin strap should not be removed, because they can serve as sites of neutral traction. The first step is to hold the head and neck in the neutral position to immobilize them. Then, in the following order, these assessments should be made: respiration; circulation; and level of consciousness. ${ }^{7}$ Because patients with impaired mental status tend to incur the highest risk of injury, they should be immobilized immediately. ${ }^{5}$

Unexplained hypo- or hypertonia or any abnormal findings on a neurological examination performed to assess minor trauma are relative indications for imaging of the cervical spine. The most common symptoms of pediatric cervical spine injury are neck pain and torticollis. ${ }^{29} \mathrm{Neck}$ or occipital pain that radiates to the shoulders and popping or snapping of the neck with or without pain may suggest the presence of a cervical spine injury. Palpation of the neck may reveal local tenderness, muscle spasm, or contracture and asymmetry. For initial radiographic screening, lateral, anteroposterior, and odontoid views of the cervical spine should be obtained. ${ }^{4,21}$

Recently, the need for the odontoid view has been questioned. Some experts believe that a lateral radiograph may be sufficient for evaluation of children younger than 5 years of age. ${ }^{24}$ If the patient is medically unstable, crosstable lateral radiography may be performed until his or her condition permits complete evaluation of the cervical spine. The false-negative rate for a single cross-table lateral radiograph ranges from 21 to $26 \%$; therefore, complete evaluation with either conventional radiography or CT scanning is necessary. ${ }^{30,32}$ The role of CT scanning with multiplanar reformatting in the assessment of cervical spine injury is crucial. A CT scan delineates the bone detail of the cervical spine and demonstrates fractures and the extent of bone injury far better than does MR imaging. On the other hand, MR imaging is helpful in the evaluation of trauma-related SCI; MR imaging facilitates evaluation of the extradural spaces and of the integrity of the spinal ligaments. Increased intraspinous distance, divergence of the articular processes, and widening of the posterior aspect of the disc space are indicative of pediatric cervical spine instability. ${ }^{31}$

\section{Spinal Cord Injury Without Radiographic Abnormality}

The SCIWORA is defined as an SCI with no abnormality depicted on conventional radiography or CT scans. ${ }^{8}$ Normal results on radiographs obtained in patients with cervical spine injury are probably related to a transient ligamentous deformation of the cervical spinal column. The spinal cord can be severely disrupted, even though it appears normal on radiographs. A possible explanation for SCIWORA is related to the difference in elasticity between the spinal column and the spinal cord. The less elastic spinal cord is more prone to injury when deformed. ${ }^{17,19}$ The other suggested cause of SCIWORA is ischemia that results from direct vessel injury or hypoperfusion of the spinal cord parenchyma. ${ }^{7}$ When clinical find- ings are present, MR imaging should be performed to evaluate for SCI despite the absence of radiographic abnormalities. ${ }^{17,26}$ Five specific SCI clinical syndromes have been described in SCIWORA: 1) central cord syndrome; 2) Brown-Sequard syndrome; 3) anterior spinal artery syndrome; 4) partial SCI; and 5) complete SCI. Profound or progressive paralysis occurs immediately or after a short latency period (usually within 48 hours); transient symptoms can also occur, such as numbness, paresthesias, paresis, or shocklike sensations in the extremities. This delay in diagnosis may be secondary to the development of spinal cord ischemia or spinal instability. ${ }^{11}$ Because a child often is unresponsive to commands or is medically unstable, an accurate neurological examination may be difficult. The prognosis depends on the degree of SCI. . $^{5,7,8,11}$

\section{Return to Play?}

The decision on whether the pediatric athlete can return to playing sports is complex and must be considered on an individual basis, after the extent of the spine injury and all other injuries are assessed. Cantu ${ }^{5}$ recommends that prior to return to play, the athlete should have no neck tenderness or spasm, neck or arm pain, numbness, paresthesias, or weakness, either at rest, with full range of motion, or on axial compression.

To help establish objective guidelines for return to play following an injury, Watkins, ${ }^{35}$ proposed a point grading system to quantify the patient's clinical situation. This system was meant as a guideline for return to play. These investigators looked at three topics and assigned point values as follows: 1) extent of the neurological injury (1 point, unilateral arm numbness or dysesthesias or loss of strength; 2 points, bilateral loss of motor or sensory function in the arms; 3 points, ipsilateral arm and leg symptoms; 4 points, transitory quadriparesis; and 5 points, transitory quadriplegia); 2 ) the time from injury to treatment ( 1 point, $<5$ minutes; 2 points, $<1$ hour; 3 points, $<24$ hours; 4 points, $<1$ week; and 5 points, $>1$ week); and $3)$ the narrowing of the central canal diameter (1 point, $>12 \mathrm{~mm} ; 2$ points, between 12 and $10 \mathrm{~mm} ; 3$ points, $10 \mathrm{~mm} ; 4$ points, between 10 and $8 \mathrm{~mm}$; and 5 points, $<8 \mathrm{~mm}$ ). The points tabulated from each of the three categories were then scaled. Patients with 0 to 6 points were thought to have minimal risk of injury with return to play; 6 to 10 points represented moderate risk; and 10 to 15 points was associated with high risk.

\section{Conclusions}

Athletic injury is a significant cause of morbidity in pediatric patients. The pediatric cervical spine has unique anatomical and developmental considerations that vary with age. Predisposing medical conditions and the mechanism of injury are important in determining the severity of the injury. Immobilization with a rigid collar is essential until spinal stability and the absence of neurological compromise are proven. The decision to return to play must be made on an individual basis, often by a multidisciplinary team including neurosurgeons, pediatricians, coaches, and family. 


\section{References}

1. Bonadio WA: Cervical spine trauma in children. I. General concepts, normal anatomy, radiographic evaluation. Am J Emerg Med 11:158-165, 1993

2. Brown RL, Brunn MA, Garcia VF: Cervical spine injuries in children: a review of 103 patients treated consecutively at a level 1 pediatric trauma center. J Pediatr Surg 36:1107-1114, 2001

3. Bruce DA, Schut L, Sutton LN: Brain and cervical spine injuries occurring during organized sports activities in children and adolescents. Prim Care 11:175-194, 1984

4. Buhs C, Cullen C, Klein M, Farmer D: The pediatric trauma Cspine: is the 'odontoid' view necessary? J Pediatr Surg 35: 994-997, 2000

5. Cantu RC: Criteria for return to competition after head or cervical spine injury, in Cantu RC, Micheli LJ (eds): American College of Sports Medicine's Guidelines for the Team Physician. Philadelphia: Lea \& Febiger, 1991, pp 205-208

6. Cattell HS, Filtzer DL: Pseudosubluxation and other normal variations in the cervical spine in children. J Bone Joint Surg Am 47:1295-1309, 1965

7. Choi JU, Hoffman HJ, Hendrick EB, Humphreys RP, Keith WS: Traumatic infarction of the spinal cord in children. J Neurosurg 65:608-610, 1986

8. Dickman CA, Zabramski JM, Rekate HL, Sonntag VK: Spinal cord injuries in children without radiographic abnormalities. West J Med 158:67-68, 1993

9. Dietrich AM, Ginn-Pease ME, Bartowski HM, King DR: Pediatric cervical spine fractures: predominantly subtle presentation. J Pediatr Surg 26:995-1000, 1991

10. Eleraky MA, Theodore N, Adams M, Rekate HL, Sonntag VKH: Pediatric cervical spine injuries: report of 102 cases and review of the literature. J Neurosurg 92 (1 Suppl):12-17, 2000

11. Grabb PA, Pang D: Magnetic resonance imaging in the evaluation of spinal cord injury without radiographic abnormality in children. Neurosurgery 35:406-414, 1994

12. Gray H: Gray's Anatomy, ed 37. Philadelphia: Lea \& Febiger, 1989

13. Herman MJ, Pizzutillo PD: Cervical spine disorders in children. Orthop Clin North Am 30:457-466, 1999

14. Hill SA, Miller CA, Kosnik EJ, Hunt WE: Pediatric neck injuries. A clinical study. J Neurosurg 60:700-706, 1984

15. Kewalramani LS, Kraus JF, Sterling HM: Acute spinal-cord lesions in a pediatric population: epidemiological and clinical features. Paraplegia 18:206-219, 1980

16. Kokoska ER, Keller MS, Rallo MC, Weber TR: Characteristics of pediatric cervical spine injuries. J Pediatr Surg 36: 100-105, 2001

17. Kriss VM, Kriss TC: SCIWORA (spinal cord injury without radiographic abnormality) in infants and children. Clin Pediatr (Phila) 35:119-124, 1996

18. Ladd AL, Scranton PE: Congenital cervical stenosis presenting as transient quadriplegia in athletes. Report of two cases. J Bone Joint Surg Am 68:1371-1374, 1986

19. Leventhall H: Birth injuries of the spinal cord. J Pediatr 56: $447-453,1960$
20. Marx JA: Rosen's Emergency Medicine: Concepts and Clinical Practice, ed 5. St. Louis: Mosby, 2002, pp 274-276

21. Mitchell CW: The normal cervical spine, in Harris JH Jr, Mirvis SE (eds): The Radiology of Acute Cervical Spine Trauma, ed 3. Baltimore: Williams \& Wilkins, 1996, pp 1-73

22. Nakajima K, Miyaoka M, Sumie H, Nakazato T, Ishii S: Cervical radiculomyelopathy due to calcification of the ligamenta flava. Surg Neurol 21:479-488, 1984

23. Odor JM, Watkins RG, Dillin WH, Dennis S, Saberi M: Incidence of cervical spinal stenosis in professional and rookie football players. Am J Sports Med 18:507-509, 1990

24. Ogden JA: Radiology of postnatal skeletal development. XI. The first cervical vertebra. Skeletal Radiol 12:12-20, 1984

25. Ogden JA: Spine, in Skeletal Injury in the Child, ed 2. Philadelphia: Saunders, 1990, pp 571-582

26. Pang D, Wilberger JG Jr: Spinal cord injury without radiographic abnormalities in children. J Neurosurg 57:114-129, 1982

27. Patel JC, Tepas JJ III, Mollitt DL, Pieper P: Pediatric cervical spine injuries: defining the disease. J Pediatr Surg 36: 373-376, 2001

28. Reynolds R: Pediatric spinal injury. Curr Opin Pediatr 12: 67-71, 2000

29. Roche C, Carty H: Spinal trauma in children. Pediatr Radiol 31: 677-700, 2001

30. Shaffer MA, Doris PE: Limitation of the cross table lateral view in detecting cervical spine injuries: a retrospective analysis. Ann Emerg Med 10:508-513, 1981

31. Swischuk LE: The spine and spinal cord, in Emergency Imaging of the Acutely Ill or Injured Child, ed 4. Philadelphia: Lippincott Williams \& Wilkins, 2000, pp 532-587

32. Torg JS: Epidemiology, pathomechanics, and prevention of athletic injuries to the cervical spine. Med Sci Sports Exerc 17: 295-303, 1985

33. Torg JS, Pavlov H, Genuario SE, Sennett B, Wisneski RJ, Robie $\mathrm{BH}$, et al: Neurapraxia of the cervical spinal cord with transient quadriplegia. J Bone Joint Surg Am 68:1354-1370, 1986

34. Torg JS, Vegso JJ, Sennett B, Das M: National Football Head and Neck Injury Registry: 14-year report on cervical quadriplegia, 1971 through 1984. JAMA 254:3439-3443, 1985

35. Watkins RG: Neck injuries in football players. Clin Sports Med 5:215-246, 1986

36. Young JE, Cantu RC: Life-threatening emergencies, in Cantu RC, Micheli LJ (eds): American College of Sports Medicine's Guidelines for the Team Physician. Philadelphia: Lea \& Febiger, 1991, pp 143-150

Manuscript received July 18, 2006.

Accepted in final form September 7, 2006.

Address reprint requests to: John A. Jane Jr, M.D., Department of Neurological Surgery, University of Virginia Health Sciences Center, P.O. Box 800212, Charlottesville, Virginia 22908-00212. email: jaj2k@virginia.edu. 